\title{
Assessment of Physical Workload of Choker Setter in Tree-length Extraction Operation by Cable Yarder
}

\author{
Min-Jae Cho, ${ }^{1}$ Eung-Jin Jeong, ${ }^{2}$ Eunjai Lee, ${ }^{1}$ Jae-Heun Oh, ${ }^{1}$ and Sang-Kyun Han ${ }^{2 *}$ \\ ${ }^{1}$ Forest Technology and Management Research Center, National Institute of Forest Science, \\ 498 Gwangneungsumogwon-ro, Soheul-eup, Pocheon-si, Gyeonggi-do 11186, South Korea \\ ${ }^{2}$ Division of Forest Sciences, College of Forest and Environmental Sciences, Kangwon National University, \\ 1 Kangwondaehak-gil, Chuncheon-si, Gangwon-do 24341, South Korea
}

(Received August 30, 2021; accepted October 22, 2021)

Keywords: cable yarding, physiological workload, relative heart rate, treadmill test, wearable electronic device

Cable yarding operations on steep terrain have always been a challenge with respect to safety as they are mostly undertaken by manual laborers, particularly in South Korea. Steep slopes are associated with a high workload for choker setters. Therefore, the main goals of this study were to determine the heart rate and oxygen consumption of choker setters and evaluate their workload during clear-cut operations on a Larix kaempferi stand using a Polar M400, H7 heart rate sensor. Three choker setters were continuously evaluated during one working day. Overall, the mean working heart rate $\left(\mathrm{HR}_{\mathrm{w}}\right)$ during choking operations ranged from 87 to $104 \mathrm{bpm}$ at a maximum oxygen consumption rate of 0.9 to $1.4 \mathrm{~L} / \mathrm{min}$. The choker setters recorded most of the effective work time on the "wait" (68.5\%) and "walk-in" (7.8\%) work elements. In addition, the physiological workload differed among the various elements of the cable yarding operation, with a higher $\mathrm{HR}_{\mathrm{w}}$ associated with a higher workload. Our findings may provide useful information for managing the health and safety of forestry crews during cable extraction activities.

\section{Introduction}

Various forest operations have relatively high safety risks as they are completed outside in all weathers, and operators are required to cover long distances during a workday in isolated locations. ${ }^{(1,2)}$ Although there are differences in mechanized forestry and timber-harvesting equipment, all of these tools require human intervention; such human intervention has economic, social, and environmental advantages. ${ }^{(3)}$ In addition, intermediate logging technology, which is defined as motor-manual felling and processing exclusively teamed with extraction machines (e.g., skidders and cable yarders), is widely used to reduce operating expenses, particularly in Europe and South Korea. ${ }^{(4-6)}$ Thus, motor-manual harvesting has been associated with a high risk of occupational health and safety problems.

The incidence of fatal accidents is considerably higher in forestry than in other industries, such as agriculture, fishing, and construction. For example, Garland ${ }^{(7)}$ reported that the rate of

*Corresponding author: e-mail: hsk@kangwon.ac.kr https://doi.org/10.18494/SAM.2021.3607 
fatal injuries (FIR) among logging workers [136 fatalities per 100000 full-time equivalent workers (FTEs)] in the United States during 2016 was 34 times higher than the all-worker FIR (4 fatalities per 100000 FTEs). Moreover, fatal accident rates in the forestry sector were seven times higher than the annual average FIR in New Zealand during the period 2006 to 2012. In Korean forestry, the FIR during 2020 (1016 fatalities per 100000 FTEs) was 1.3 times greater than the annual average FIR ( 810 fatalities per 100000 FTEs). ${ }^{(8)}$ Fatal accidents are related to intensive work associated with task demands, piecework, face-moving, and inadequate training. ${ }^{(3,9)}$ Furthermore, fellers and choker setters perform more strenuous work than chasers and machine operators. ${ }^{(7,10)}$ Hence, it is necessary to investigate physical and mental fatigue to determine the energy expenditure and provide a suitable work-rest regimen in this industry.

Heart rate (HR) and oxygen consumption increment have been widely used to evaluate physiological workload. ${ }^{(3,11)}$ Heart rate monitoring (HRM) methods have been broadly applied to understand physical and mental workload changes in real time, ${ }^{(12-14)}$ as well as to determine the heart strain, as an accessible predictor of cardiovascular activities to monitor forest worker health and safety. ${ }^{(11)}$ Although real-time signal monitoring can detect changes immediately, it also has challenges, including the natural variation in signal and the change in point detection (CPD). ${ }^{(13)}$ However, it may be justifiable to assume HR variability since CPD is widely used in the investigation of biomedical problems. ${ }^{(13)}$ Additionally, several previous studies have assessed workload using the maximum oxygen consumption capacity $\left(\mathrm{VO}_{2 \mathrm{max}}\right)$, but this is difficult to record under field conditions. ${ }^{(3,5)}$ An alternative method is to perform a maximal incremental running test on a treadmill. ${ }^{(15)}$ Indeed, previous studies, which are mainly case reports on forest operations, provided a physical workload evaluation of forest crews by HRM.

Most Korean forests are located in steep mountainous areas (approximately 54\%) with complex terrains. ${ }^{(16)}$ In Korea, a common method for the mechanical extraction of trees is to use a cable yarder, which is ideally suited for steep-slope harvesting. ${ }^{(17)}$ In cable yarding, trees are cut using chainsaws, and rigging choker setters set up cables around them by hand, which are used for extraction uphill to a landing field.(6) The choker setter operation is associated with potentially fatal accident risks, such as pinch-point and rollover injuries, because a yarder and a worker work simultaneously on a steep terrain. ${ }^{(18)}$ Therefore, this technology has not been adopted in places where choker setters are exposed to these occupational hazards, particularly in the United States. ${ }^{(19)}$

Several previous studies have determined the performance of cable yarders to expand and improve the efficiency of wood production and supply chains in South Korea. ${ }^{6,20,21)}$ However, to our knowledge, none of the previous studies explicitly determined the physical workload of choker setters. Therefore, in this study we aimed to (1) determine $\mathrm{HR}$ and $\mathrm{VO}_{2 \max }$ variability for choker setters and the specific work process that incurs the highest workload, and (2) evaluate the total physical workload during cable yarding operations using a HAM300 tower yarder during the tree-length harvesting method. 


\section{Materials and Methods}

\subsection{Overview of the study area}

The target site of the study was at 11 Ungyo-ri, Bangrim-myeon, Pyeongchang-gun, Gangwon-do ( $37^{\circ} 26^{\prime} 21^{\prime \prime} \mathrm{N}$ and $\left.128^{\circ} 15^{\prime} 44^{\prime \prime} \mathrm{E}\right)$, which is forest of age class VI (51-60 years) and has been the site of clear-cut operations over an area of 2.1 ha, producing an average tree volume of $0.92 \mathrm{~m}^{3} /$ tree in a Larix kaempferi stand (Table 1, Fig. 1). In addition, a $100 \mathrm{hp}$ tractor-attached HAM300 tower yarder was used to implement cable yarding operations. The average lateral distance of the uphill cable yarding operation was $11 \mathrm{~m}$, the average yarding distance was $91 \mathrm{~m}$, and the average slope was $40 \%$.

Table 1

Description of the study area.

\begin{tabular}{lc}
\hline Item & Contents \\
\hline Area (ha) & 2.1 \\
Type & Coniferous forest \\
Species & Larix kaempferi \\
Age class & VI \\
Average slope $(\%)$ & 40 \\
Average height $(\mathrm{m})$ & 23 (range: $16-29)$ \\
Average diameter at breast height $(\mathrm{cm})$ & 34 (range: $14-60)$ \\
\hline
\end{tabular}

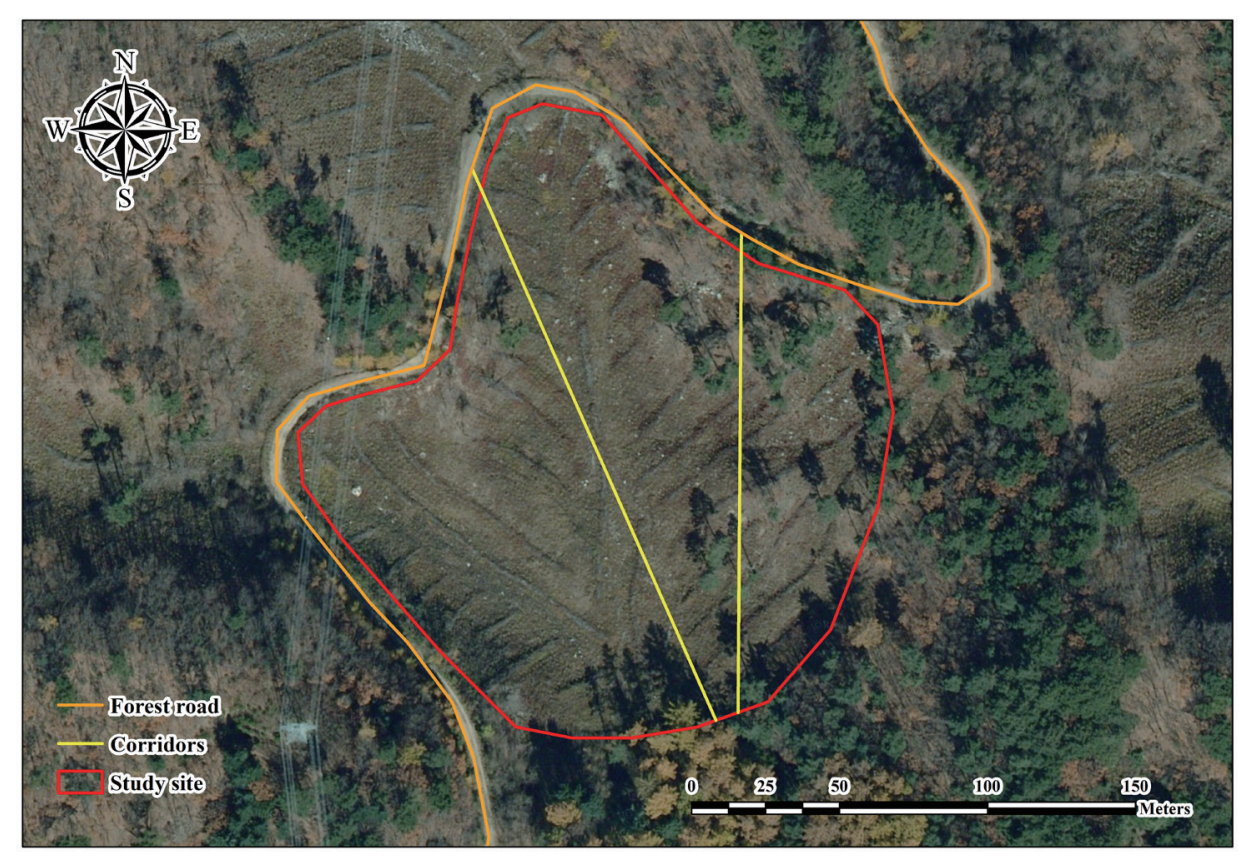

Fig. 1. (Color online) Study site. 


\subsection{Anthropometry and body composition of choker setters}

Cable yarding operations were performed by groups of four workers (one operator and three choker setters), and the workload was measured among the three choker setters in the stump area. Experiments were conducted after explaining the purpose and methods of this study to the choker setters. The age and experience of each choker setter were examined, and the height, weight, and body mass index (BMI) were measured using the Lookin' Body Health Care System. BMI was classified into four categories based on the World Health Organization's classification: ${ }^{(22)}$ underweight $(<18.5)$, normal weight (18.5-24.9), overweight (25-29.9), and obese $(\geq 30)$. $^{(3,23)}$

\subsection{Maximum oxygen consumption}

First, an indoor exercise load test was conducted at Baengnyeong Sports Center at Kangwon National University to estimate the $\mathrm{VO}_{2 \max }$ of the choker setters. For the test, an M400 H7 cardiometer (Polar Global, Kempele, Finland), a treadmill (MTM-1500; Schiller, Baar, Switzerland) to change the exercise intensity, and a gas analyzer (Quark Cardio Pulmonary Exercise Test; Cosmed, Rome, Italy) were used to measure the $\mathrm{O}_{2}$ and $\mathrm{CO}_{2}$ concentrations (Fig. 2).

The exercise load was measured while applying the Bruce protocol, which was developed to induce workers to be active; in this protocol, the speed is increased by $1.28 \mathrm{~km} / \mathrm{h}$ and the incline is increased by $2 \%$ every 3 min (Fig. 3). ${ }^{(24)}$ We developed a model that predicts $\mathrm{VO}_{2 \max }$ according to the changes in HR with the measured data. The workload of the workers was also analyzed using $\mathrm{VO}_{2 \max }$, increased heart rate (IHR), and relative heart rate (HRR). ${ }^{(21,25)}$

\subsection{HR}

The HR of the choker setters was measured during operations in the field using a Polar M400, H7 HR sensor, consisting of a belt-type sensor that is attached to the chest and measures the cardiac rate at $1 \mathrm{~s}$ intervals, and a wristwatch-type device that wirelessly transmits and receives the data (Fig. 4).

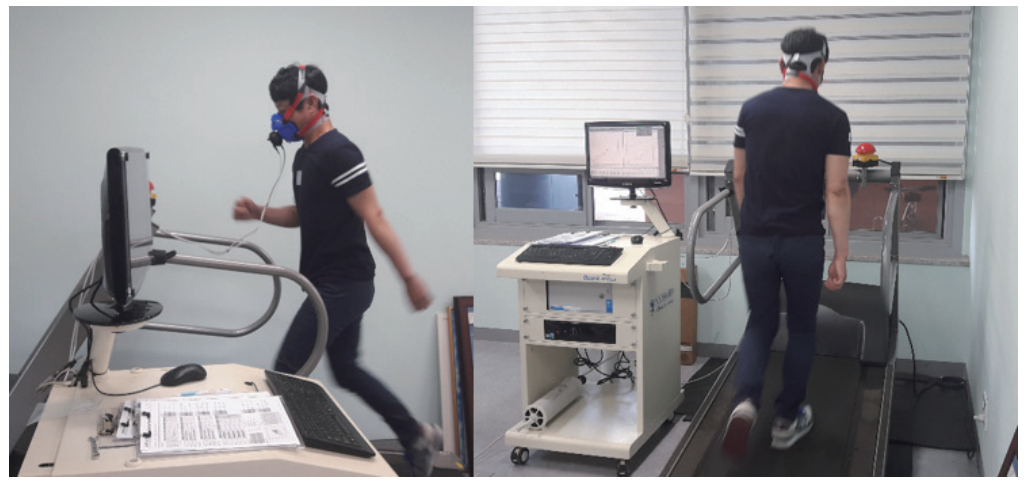

Fig. 2. (Color online) Indoor exercise load test. 


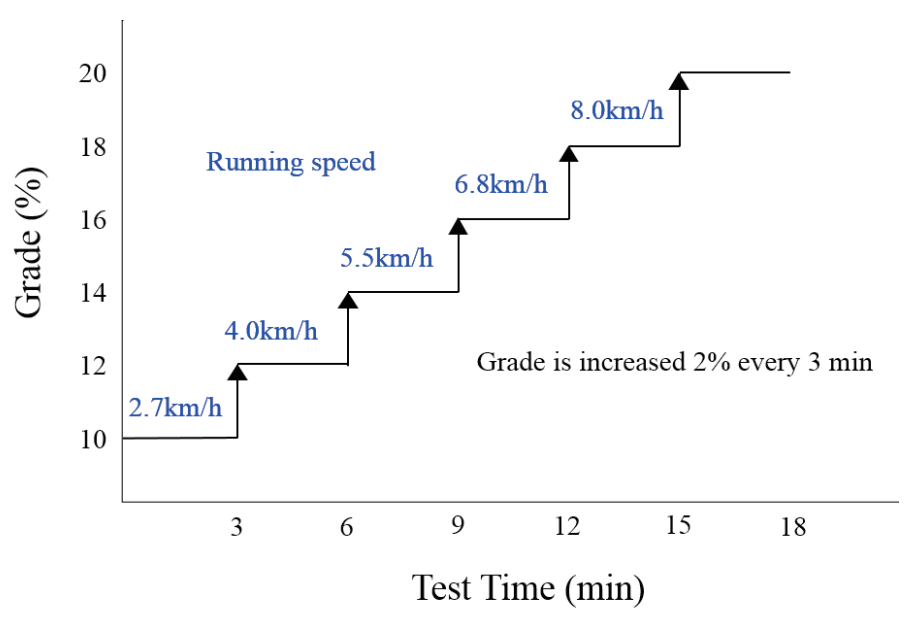

Fig. 3. (Color online) Bruce protocol according to Myers and Froelicher. ${ }^{(24)}$

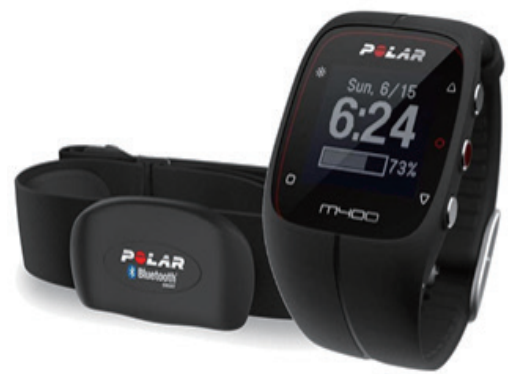

Fig. 4. (Color online) Polar M400, H7 device used for HR measurements.

The resting heart rate $\left(\mathrm{HR}_{\mathrm{r}}, \mathrm{bpm}\right)$, working heart rate $\left(\mathrm{HR}_{\mathrm{w}}, \mathrm{bpm}\right)$, and maximum heart rate $\left(\mathrm{HR}_{\max }, \mathrm{bpm}\right)$ were measured to analyze IHR (\%) and HRR (\%) as follows: ${ }^{(3,21)}$

$$
\begin{gathered}
I H R=\frac{H R_{w}-H R_{r}}{H R_{r}} \times 100, \\
H R R=\frac{H R_{w}-H R_{r}}{H R_{\max }-H R_{r}} \times 100 .
\end{gathered}
$$

The $\mathrm{HR}_{\mathrm{w}}$ measurement required the choker setters to sit and rest for $15 \mathrm{~min}$ before starting to work, during which time they were prohibited from talking, consuming food, and smoking. ${ }^{(5)}$ $\mathrm{HR}_{\mathrm{w}}$ is the average heart rate during working hours, including breaks. $\mathrm{HR}_{\max }$ was estimated using the Rodahl formula $\left(\mathrm{HR}_{\max }=220-\right.$ age $),{ }^{(25)}$ in which heart rate increases linearly with the exercise load, then reaches its maximum limit at exhaustion. ${ }^{(5)}$ IHR was used to assess the workload of each task when workers performed several tasks. However, a direct comparison among different workers was not possible. Instead, HRR was used to correct disparities among workers. Using the HR and HRR of each choker setter, the workload levels were evaluated using the categories in Table 2.(26,27) 
Table 2

Classification of workload regarding maximum oxygen consumption $\left(\mathrm{VO}_{2 \max }\right), \mathrm{HR}$, and HRR.

\begin{tabular}{lccc}
\hline Workload level & $\mathrm{VO}_{2 \max }(\mathrm{L} / \mathrm{min})$ & $\mathrm{HR}(\mathrm{bpm})$ & $\mathrm{HRR}(\%)$ \\
\hline Light & $<0.5$ & $<90$ & $<30$ \\
Moderate & $0.5-1.0$ & $91-110$ & $31-40$ \\
Heavy & $1.1-1.5$ & $111-130$ & $41-50$ \\
Very heavy & $1.6-2.0$ & $133-150$ & $51-60$ \\
Extremely heavy & $>2.1$ & $>151$ & $>61$ \\
\hline
\end{tabular}

\subsection{Time study}

A time study was conducted simultaneously with the HR measurements. The work process of each choker setter was videotaped to measure the workload of each element of the cable yarding operations. This information was synchronized with the data recorded by the HR sensor. The tasks were performed consecutively, and the work elements were separated as follows: (1) walkin: moving from the safety area to a carriage arriving at the yarding location, (2) pulling: pulling the wire rope up, down, left, and right from the carriage to make it easier for other workers to drag; (3) dragging: dragging the wire rope to the yarding area; (4) hooking: wrapping the wire rope around the yarding area; (5) walk-out: moving to the safety area after installing the choker; (6) wait: waiting in the safety area for the carriage to return, and (7) rest: halting work and resting.

\section{Results and Discussion}

\subsection{Anthropometric and personal information}

The physical characteristics of the three choker setters are presented in Table 3. Worker $\mathrm{K}$ had a BMI of $27.8 \mathrm{~kg} / \mathrm{m}^{2}$ and was classified as overweight, whereas workers $\mathrm{J}$ and $\mathrm{U}$ were classified within the normal weight category with BMIs of 21.3 and $21.6 \mathrm{~kg} / \mathrm{m}^{2}$, respectively. The workers had at most 4 years of work experience.

\subsection{Time study and HR variability}

The average yarding time of a single volume of cable yarding was 533 s/cycle, and the times required for each choker setter to perform the different tasks are listed in Table 4. For all workers, the greatest amount of time was spent on the "wait" element, i.e., waiting for the carriage to return from the safety area (67.4-69.7\%). The analysis of the time taken on each primary task showed that worker $\mathrm{K}$ pulled the rope in $54 \mathrm{~s}(10.1 \%)$, worker $\mathrm{J}$ dragged the rope in $13 \mathrm{~s}(2.5 \%)$, and worker $\mathrm{U}$ hooked the choker installation in $38 \mathrm{~s}$ (7.2\%) (Table 4). Moreover, worker $\mathrm{J}$ took a longer time pulling and hooking than dragging, while the time taken delivering wires was between those required for workers $\mathrm{K}$ and $\mathrm{U}$.

$\mathrm{HR}_{\mathrm{w}}, \mathrm{HR}_{\mathrm{r}}$, and IHR data per work element for the three choker setters are also shown in Table 4. Workers K, U, and $\mathrm{J}$ had $\mathrm{HR}_{\mathrm{w}}$ values of $90 \pm 10.3 \mathrm{bpm}, 94 \pm 18.3 \mathrm{bpm}$, and $79 \pm 14.5$ 
Table 3

Characteristics of the choker setters.

\begin{tabular}{lccccccc}
\hline $\begin{array}{l}\text { Choker } \\
\text { setter }\end{array}$ & $\begin{array}{c}\text { Age } \\
(\text { years })\end{array}$ & $\begin{array}{c}\text { Height } \\
(\mathrm{cm})\end{array}$ & $\begin{array}{c}\text { Weight } \\
(\mathrm{kg})\end{array}$ & $\begin{array}{c}\mathrm{BMI}^{\mathrm{a}} \\
\left(\mathrm{kg} / \mathrm{m}^{2}\right)\end{array}$ & $\begin{array}{c}\text { Body fat } \\
(\%)\end{array}$ & Skill level & $\begin{array}{c}\text { Job experience } \\
(\text { year })\end{array}$ \\
\hline $\mathrm{K}$ & 60 & 169 & 80 & 27.8 & 29 & Medium & 3 \\
$\mathrm{~J}$ & 41 & 162 & 57 & 21.3 & 16 & Medium & 4 \\
$\mathrm{U}$ & 54 & 165 & 59 & 21.6 & 16 & Medium & 2 \\
\hline
\end{tabular}

${ }^{a}$ Reference values of body mass index (BMI): underweight ( $\left.<18.5\right)$, normal weight (18.5-24.9), overweight (25-29.9), and obese $(\geq 30)$.

Table 4

Time consumption, frequency, $\mathrm{HR}_{\mathrm{W}}$, IHR, and HRR for each work element.

\begin{tabular}{|c|c|c|c|c|c|c|c|c|c|}
\hline \multicolumn{2}{|c|}{ Choker setter } & Walk-in & Pulling & Dragging & Hooking & Walk-out & Wait & Rest & $\begin{array}{c}\text { Mean } \\
\left( \pm \mathrm{SD}^{\mathrm{e}}\right)\end{array}$ \\
\hline \multirow{5}{*}{$\mathrm{K}^{\mathrm{a}}$} & $\operatorname{Time}^{\mathrm{d}}(\mathrm{s})$ & 42 & 54 & 16 & 1 & 43 & 359 & 19 & - \\
\hline & Frequency (\%) & 7.8 & 10.1 & 2.9 & 0.2 & 8.0 & 67.4 & 3.5 & - \\
\hline & $\mathrm{HR}_{\mathrm{W}}(\mathrm{bpm})$ & 91 & 104 & 102 & 103 & 100 & 87 & 82 & $90(10.3)$ \\
\hline & IHR (\%) & 30 & 49 & 46 & 47 & 42 & 24 & 17 & 29 (14.7) \\
\hline & HRR (\%) & 23 & 37 & 35 & 36 & 33 & 19 & 13 & $22(11.3)$ \\
\hline \multirow{5}{*}{$\mathrm{J}^{\mathrm{b}}$} & Time $^{\mathrm{d}}(\mathrm{s})$ & 51 & 23 & 13 & 4 & 37 & 365 & 40 & - \\
\hline & Frequency (\%) & 9.6 & 4.3 & 2.5 & 0.7 & 7.0 & 68.4 & 7.5 & - \\
\hline & $\mathrm{HR}_{\mathrm{W}}(\mathrm{bpm})$ & 93 & 107 & 101 & 102 & 107 & 89 & 76 & $94(18.3)$ \\
\hline & IHR (\%) & 56 & 79 & 68 & 70 & 79 & 47 & 27 & $57(30.5)$ \\
\hline & HRR $(\%)$ & 28 & 40 & 34 & 35 & 40 & 24 & 13 & $29(15.4)$ \\
\hline \multirow{5}{*}{$\mathrm{U}^{\mathrm{c}}$} & $\operatorname{Time}^{\mathrm{d}}(\mathrm{s})$ & 32 & 3 & 17 & 38 & 43 & 372 & 28 & - \\
\hline & Frequency (\%) & 5.9 & 0.6 & 3.2 & 7.2 & 8.1 & 69.7 & 5.3 & - \\
\hline & $\mathrm{HR}_{\mathrm{W}}(\mathrm{bpm})$ & 87 & 95 & 83 & 87 & 94 & 76 & 64 & 79 (14.5) \\
\hline & IHR (\%) & 49 & 63 & 42 & 49 & 62 & 31 & 10 & $35(25.0)$ \\
\hline & HRR (\%) & 26 & 33 & 22 & 26 & 33 & 16 & 5 & 19 (13.2) \\
\hline
\end{tabular}

Resting heart rate (bpm): ${ }^{\mathrm{a}} 70,{ }^{\mathrm{b}} 60,{ }^{\mathrm{c}} 58$

Total time: ${ }^{\mathrm{d}} 533 \mathrm{~s}$

${ }^{\mathrm{e}} \mathrm{Standard}$ deviation

bpm (mean \pm standard deviation), respectively. Kim et al. ${ }^{(28)}$ and Kirk and Sullman ${ }^{(29)}$ found that $\mathrm{HR}_{\mathrm{w}}$ ranged between $88 \pm 4.7 \mathrm{bpm}$ and $106 \pm 6.9 \mathrm{bpm}$ in choker-setting operations and confirmed the primary effect of BMI on $\mathrm{HR}_{\mathrm{w}}$. Similar results were found in our study except for worker J.

Worker $\mathrm{K}$ had the highest $\mathrm{HR}_{\mathrm{w}}$ at $104 \mathrm{bpm}$ while pulling, followed by hooking (103 bpm), dragging (102 bpm), walk-out (100 bpm), walk-in (91 bpm), wait (87 bpm), and rest (87 bpm) (Table 4). The $\mathrm{HR}_{\mathrm{w}}$ of worker J was higher during pulling (107 bpm) and hooking (102 bpm) than during dragging (101 bpm). Worker $U$ had the highest $\mathrm{HR}_{\mathrm{w}}$ at $95 \mathrm{bpm}$ while pulling and the lowest at $76 \mathrm{bpm}$ while waiting, excluding rest. The $\mathrm{HR}_{\mathrm{r}}$ values of workers $\mathrm{K}$, J, and $\mathrm{U}$ were 70 , 60, and $58 \mathrm{bpm}$, respectively. Moreover, the calculated IHR based on $\mathrm{HR}_{\mathrm{w}}$ and $\mathrm{HR}_{\mathrm{r}}$ was found to be $57 \pm 30.5 \%$ for worker $\mathrm{J}$, which was higher than those for workers $\mathrm{K}(29 \pm 14.7 \%)$ and $\mathrm{U}$ $(35 \pm 25.0 \%)$ (Table 4$)$.

HRR for each work element was found to be $22 \pm 11.3 \%$ for worker K, $29 \pm 15.4 \%$ for worker $\mathrm{J}$, and $19 \pm 13.2 \%$ for worker U (Table 4). These results were consistent with previous studies by 
Kim et al. ${ }^{(28)}$ and Kirk and Sullman, ${ }^{(29)}$ who reported HRRs ranging from $26.6 \pm 3.7 \%$ to $36.4 \pm 3.1 \%$, respectively. In addition, the HRRs obtained for pulling (33-40\%), dragging (22-35\%), and hooking (26-36\%), which required transport, were higher than those obtained for all the other tasks (5-28\%), which did not require transport, except for the task of walk-out, which involved supporting the weight of the wire rope and choker (Table 4). These results are similar to those reported by Spinelli et al., ${ }^{(5)}$ who evaluated HRR on the basis of whether the equipment was used in choker-setting operations. HRR for equipment-driven choker-setting operations was found to be $35-54 \%$, which was higher than the value of $32-44 \%$ observed when no equipment was used. ${ }^{(5)}$ HRR for walk-out was also found to be high at $33-40 \%$. These results demonstrate that the preceding workload (pulling, dragging, and hooking) affected the following work element (walk-out).

\subsection{Prediction of maximum oxygen consumption rate}

A regression equation was derived for each of the three workers to predict $\mathrm{VO}_{2 \max }$ using $\mathrm{HR}$ from the indoor exercise load test (Table 5). $\mathrm{HR}$ and $\mathrm{VO}_{2 \max }$ showed a statistically significant correlation, and $\mathrm{VO}_{2 \max }$ for each work element at the site is shown in Table 6. $\mathrm{VO}_{2 \max }$ was determined to be $1.09 \pm 0.28 \mathrm{~L} / \mathrm{min}$ for worker $\mathrm{K}, 0.79 \pm 0.27 \mathrm{~L} / \mathrm{min}$ for worker $\mathrm{J}$, and $1.14 \pm 0.15 \mathrm{~L} / \mathrm{min}$ for worker $\mathrm{U}$ (Table 6 ).

\subsection{Assessment of physical workload}

The level of workload during each task, determined on the basis of $\mathrm{HR}, \mathrm{HRR}$, and $\mathrm{VO}_{2 \max }$, for each choker setter is shown in Table 7. Rope pulling by worker $\mathrm{K}$ was assessed as having a moderate workload on the basis of HR (104 bpm) and HRR (37.5\%) but as having a heavy workload on the basis of $\mathrm{VO}_{2 \max }(1.4 \mathrm{~L} / \mathrm{min})$. Rope dragging by worker $\mathrm{J}$ was assessed as having a moderate workload on the basis of $\mathrm{HR}(101 \mathrm{bpm}), \mathrm{HRR}(34.2 \%)$, and $\mathrm{VO}_{2 \max }(0.9 \mathrm{~L} / \mathrm{min})$.

Table 5

Relationship between heart rate and maximum oxygen consumption $\left(\mathrm{VO}_{2 \max }\right)$ during the work load test.

\begin{tabular}{lccc}
\hline $\begin{array}{l}\text { Choker } \\
\text { setter }\end{array}$ & Regression equation for estimating $\mathrm{VO}_{2 \max }{ }^{\mathrm{a}}$ & $R^{2}$ & $p$-value \\
\hline $\mathrm{K}$ & $y=0.032 x-1.929$ & 0.89 & $<0.0001$ \\
$\mathrm{~J}$ & $y=0.024 x-1.508$ & 0.92 & $<0.0001$ \\
$\mathrm{U}$ & $y=0.014 x+0.049$ & 0.84 & $<0.0001$ \\
\hline
\end{tabular}

${ }^{\mathrm{a}} y, \mathrm{VO}_{2 \max }(\mathrm{L} / \mathrm{min}) ; x$, heart rate (bpm)

Table 6

Maximum oxygen consumption for each work element (L/min).

\begin{tabular}{lcccccccc}
\hline $\begin{array}{l}\text { Choker } \\
\text { setter }\end{array}$ & Walk-in & Pulling & Dragging & Hooking & Walk-out & Wait & Rest & Mean $\left( \pm \mathrm{SD}^{\mathrm{a}}\right)$ \\
\hline $\mathrm{K}$ & 0.96 & 1.37 & 1.31 & 1.32 & 1.23 & 0.82 & 0.65 & $1.09(0.28)$ \\
$\mathrm{J}$ & 0.72 & 1.04 & 0.89 & 0.92 & 1.05 & 0.59 & 0.30 & $0.79(0.27)$ \\
$\mathrm{U}$ & 1.18 & 1.30 & 1.13 & 1.18 & 1.29 & 1.03 & 0.86 & $1.14(0.15)$ \\
\hline
\end{tabular}

${ }^{\mathrm{a}}$ Standard deviation 
Table 7

Workload level evaluated using heart rate (HR), relative heart rate (HRR), and maximum oxygen consumption $\left(\mathrm{VO}_{2 \max }\right)$ for each task.

\begin{tabular}{|c|c|c|c|c|c|c|}
\hline Worker & & Task & $\begin{array}{l}\text { HR } \\
\text { (bpm) }\end{array}$ & $\begin{array}{c}\text { HRR } \\
(\%)\end{array}$ & $\begin{array}{l}\mathrm{VO}_{2 \max } \\
(\mathrm{L} / \mathrm{min})\end{array}$ & $\begin{array}{c}\text { Final workload } \\
\text { level }\end{array}$ \\
\hline \multirow{6}{*}{ In this study } & \multirow{2}{*}{ K } & Pulling & 104 & 37.5 & 1.4 & \multirow{2}{*}{ M } \\
\hline & & Workload level $^{\mathrm{a}}$ & $\mathrm{M}$ & M & $\mathrm{H}$ & \\
\hline & \multirow{2}{*}{$\mathrm{J}$} & Dragging & 101 & 34.2 & 0.9 & \multirow{2}{*}{ M } \\
\hline & & Workload level $^{\mathrm{a}}$ & $\mathrm{M}$ & M & $\mathrm{M}$ & \\
\hline & \multirow{2}{*}{ U } & Hooking & 87 & 25.9 & 1.3 & \multirow{2}{*}{$\mathrm{L}$} \\
\hline & & Workload level $^{\mathrm{a}}$ & $\mathrm{L}$ & $\mathrm{L}$ & $\mathrm{H}$ & \\
\hline \multirow{2}{*}{ Kim et al. ${ }^{(28)}$} & & Choker setters & 105 & 32.2 & - & \multirow{2}{*}{ M } \\
\hline & & Workload level $^{\mathrm{a}}$ & $\mathrm{M}$ & $\mathrm{M}$ & - & \\
\hline \multirow{2}{*}{$\begin{array}{l}\text { Kirk and } \\
\text { Sullman }\end{array}$} & & Choker setters & 106 & 36.4 & - & \multirow{2}{*}{ M } \\
\hline & & Workload level $^{\mathrm{a}}$ & M & M & - & \\
\hline \multirow{2}{*}{ Spinelli et al. ${ }^{(5)}$} & & Choker setters & 115 & 43.3 & - & \multirow{2}{*}{$\mathrm{H}$} \\
\hline & & Workload level ${ }^{\mathrm{a}}$ & $\mathrm{H}$ & $\mathrm{H}$ & - & \\
\hline
\end{tabular}

${ }^{\mathrm{a}}$ Light (L), Moderate (M), Heavy (H)

Hooking by worker $U$ was assessed as having a light workload on the basis of HR ( $87 \mathrm{bpm})$ and HRR $(25.9 \%)$ but as having a heavy workload on the basis of $\mathrm{VO}_{2 \max }(1.3 \mathrm{~L} / \mathrm{min})$ (Table 7$)$. According to Policarpo et al., ${ }^{(30)} \mathrm{HRR}$ and $\mathrm{VO}_{2 \max }$ are factors that determine the level of workload. However, as the HR ratio increased (50-80\%), $\mathrm{VO}_{2 \max }$ tended to overestimate the workload level. Therefore, it is recommended that workload levels are evaluated using HRR rather than $\mathrm{VO}_{2 \max }$. In the present study, the pulling and dragging operations by workers $\mathrm{K}$ and $\mathrm{J}$ were assessed as having a moderate workload, and the hooking operation by worker $\mathrm{U}$ was assessed as having a light workload. Previous studies such as those of Kim et al., ${ }^{(28)}$ Kirk and Sullman, ${ }^{(29)}$ and Spinelli et al. ${ }^{(5)}$ showed that the workload for choker setters ranged from moderate to heavy, and the results of this study showed a similar tendency.

\section{Conclusions}

In this study, three cable-yarding choker setters of a tree-length harvesting system using a HAM300 tower yarder were evaluated to assess the workload levels on the basis of HR, HRR, and $\mathrm{VO}_{2 \max }$. During choking operations, the greatest amount of time was spent on the "wait" work element. For all workers, IHR was the highest in the "pulling" work element. The choking operations were determined to have a moderate workload on the basis of HR and HRR and to have a heavy workload on the basis of $\mathrm{VO}_{2 \max }$. However, these results are limited to applications related to managing the health and safety of forestry crews during cable extraction activities. Further study is required to consider the fitness of workers to reduce the workload. In addition, the use of equipment for cable yarding operations, such as slack pullers, synthetic wires, and walking aids, can also help reduce the workload of workers, which is ultimately expected to improve overall productivity. 


\section{Acknowledgments}

This study was carried out with the support of the R\&D Program for Forest Science Technology (Project No. 2020212D10-2122-AC02) provided by Korea Forest Service (Korea Forestry Promotion Institute).

\section{References}

1 S. Kim, M. A. Nussbaum, A. L. Schoenfisch, S. M. Barrett, M. C. Bolding, and D. E. Dickerson: Forests 8 (2017) 440. https://doi.org/10.3390/f8110440

2 I. Potočnik and A. Poje: Croat. J. For. Eng. 38 (2017) 291.

3 Z. Arman, M. Nikooy, P. A. Tsioras, M. Heidari, and B. Majnounian: Int. J. For. Eng. 32 (2021) 91. https://doi.or g/10.1080/14942119.2021.1868238

4 K. Enez, M. Topbas, and H. H. Acar: Int. J. Ind. Ergon. 44 (2014) 621. https://doi.org/10.1016/j.ergon.2014.07.002

5 R. Spinelli, G. O. Aalmo, and N. Magagnotti: Ergonomics 58 (2015) L781. https://doi.org/10.1080/00140139.201 4.983184

6 E. J. Lee, Y. S. Choi, M. J. Cho, K. H. Cho, J. H. Oh, S. K. Han, and S. J. Im: Forests 12 (2021) 908. https://doi. org/10.3390/f12070908

7 J. J. Garland: Accident Reporting and Analysis in Forestry: Guidance on Increasing the Safety of Forest Work (Forestry Working Paper No. 2. FAO, Rome, 2018) p. 77.

8 Korea Occupational Safety and Health Agency: https://www.kosha.or.kr/kosha/index.do (accessed July 2021).

9 C. Slappendel, I. Laird, L. Kawachi, S. Marshall, and C. Cryer: J. Safety Res. 24 (1993) 19. https://doi. org/10.1016/0022-4375(93)90048-R

10 M. Jankovský, M. Allman, and Z. Allmanová: Int. J. Environ. Res. Public Health 16 (2019) 4931. https://doi. org/10.3390/ijerph16244931

11 M. Cheţa, M. V. Marcu, and S. A. Borz: Forests 9 (2018) 300. https://doi.org/10.3390/f9060300

12 M. Garet, G. Boudet, C. Montaurier, M. Vermorel, J. Coudert, and A. Chamoux: Eur. J. Appl. Physiol. 94 (2005) 46. https://doi.org/10.1007/s00421-004-1228-9

13 A. Hoover, A. Singh, S. Fishel-Brown, and E. Muth: Biomed. Signal Process. Control 7 (2012) 333. https://doi. org/10.1016/j.bspc.2011.07.004

14 D. Afshari and G. A. Shirali: Urban Clim. 27 (2019) 142. https://doi.org/10.1016/j.uclim.2018.11.008

15 A. De Brabandere, T. Op De Beéck, K. N. Schütte, W. Meert, B. Vanwanseele, and J. Davis: PLOS ONE 13 (2018) e0199509. https://doi.org/10.1371/journal.pone.0199509

16 Korea Forest Service: https://www.forest.go.kr/kfsweb/kfs/idx/Index.do (accessed July 2021).

17 R. Spinelli, E. Marchi, R. Visser, H. Harrill, R. Gallo, M. Cambi, F. Neri, C. Lombardini, and N. Magagnotti: Int. J. For. Eng. 28 (2017) 34. https://doi.org/10.1080/14942119.2016.1267970

18 S. M. Newman, R. F. Keefe, R. H. Brooks, E. Q. Ahonen, and A. M. Wempe: Safety (Basel) 4 (2018) 43. https:// doi.org/10.3390/safety4040043

19 A. M. Wempe and R. F. Keefe: Forests 8 (2017) 357. https://doi.org/10.3390/f8100357

20 M.-J. Cho, Y.-S. Choi, S.-H. Paik, H.-S. Mun, D.-S. Cha, S.-K. Han, and J.-H. Oh: Forests 10 (2019) 763. https:// doi.org/10.3390/f10090763

21 S.-A. Baek, K.-H. Cho, and E. Lee: Carr. Plantation. Sustain. 12 (2020) 8864. https://doi.org/10.3390/ $\underline{\text { su12218864 }}$

22 World Health Organization: Mean Body Mass Index, https://www.who.int/data/gho/data/themes/topics/topicdetails/GHO/body-mass-index (accessed July 2021).

23 K. Tunceli, K. M. Li, and L. K. Williams: Obesity 14 (2006) 1637. https://doi.org/10.1038/oby.2006.188

24 J. Myers and V. F. Froelicher: Circulation 82 (1990) 1839.

25 K. Rodahl: Physiology of Work (CRC Press, London, 1989).

26 E. Çalıskan and S. Çaglar: Afr. J. Biotechnol. 9 (2010).

27 S. Çağlar: Int. J. For. Eng. 32 (2021) 1. https://doi.org/10.1080/14942119.2021.1927471

28 J. W. Kim, M. S. Park, and T. Y. Song: FRI J. For. Sci. 54 (1996) 40.

29 P. M. Kirk and M. J. Sullman: Appl. Ergo. 32 (2001) 389. https://doi.org/10.1016/S0003-6870(01)00003-5

30 F. Policarpo, P. Valdivia-Moral, M. D. S. Luna-Cruz, A. Véliz-Burgos, J. Mansilla-Sepulveda, and J. G. EstaySepulveda: Sustainability 11 (2019) 6420. https://doi.org/10.3390/su11226420 